\title{
HLA haplotypes in Type 1 (insulin-dependent) diabetes mellitus: molecular analysis of the HLA-DQ locus
}

\author{
P.J.Tienari ${ }^{1}$, E. Tuomilehto-Wolf ${ }^{2}$, J.Tuomilehto ${ }^{2}$, L.Peltonen ${ }^{1}$ and the DIME Study Group* \\ ${ }^{1}$ Laboratory of Molecular Genetics and ${ }^{2}$ Department of Epidemiology, National Public Health Institute, Helsinki, Finland
}

\begin{abstract}
Summary. In Caucasians the predisposition to Type 1 (insulin-dependent) diabetes mellitus has been shown to associate with HLA-DR3,DQw2 and DR4,DQw8 and with the presence of amino acids other than aspartic acid at position 57 on the HLA-DQ $\beta$ chain. In Finland the haplotypespecific absolute risk for developing Type 1 diabetes differs between various DR 3 and DR4 positive haplotypes. The aim of our present analysis was to find out whether this variation is attributable to polymorphism at the DQ locus. As part of a nationwide prospective study including 757 serologically HLA genotyped families, we determined HLA-DQ $\alpha$ and $\mathrm{DQ} \beta$ restriction fragment polymorphisms in 17 selected families with important susceptibility haplotypes. Additionally, the DQA1 alleles were determined from 19 haplotypes using sequence-specific oligonucleotide probes, and the DQB1 second exon was sequenced from nine haplotypes. The DR3 as well as DR4 positive haplotypes frequently
\end{abstract}

found in Type 1 diabetic patients showed no variation at the HLA-DQ locus, and they were DQw2 and DQw8, respectively. The absolute risk for Type 1 diabetes for DR4,DQw8 positive haplotypes A2,Cw4,Bw35,DR4 A3,Cw3,Bw62,DR4, A24,Cw7,Bw39,DR4, A2,Cw3,Bw62, DR4, and A2,Cw1,Bw56,DR4 was 35/100,000, 130/100,000, $166 / 100,000,196 / 100,000$, and $218 / 100,000$, respectively. The absolute risks for DR3,DQw2 positive haplotypes $\mathrm{A} 1$, Cw7,B8,DR3 and A2,Cw7,B8,DR3 were $68 / 100,000$ and $103 / 100,000$, respectively. These results provide further evidence that not only the polymorphism at the DQ locus but also other genes of the haplotypes contribute to susceptibility to Type 1 diabetes.

Key words: Type 1 (insulin-dependent) diabetes mellitus, HLA haplotypes, HLA-DQ, restriction fragment length polymorphism, genetics, disease susceptibility.
Type 1 (insulin-dependent) diabetes mellitus is one of the diseases in which the study of the HLA system at the molecular level has provided new insights into disease susceptibility. However, controversy exists as to whether one or several HLA loci contribute in determining predisposition to Type 1 diabetes. After the initial findings of positive associations with HLA-B8, B15, and B18, stronger associations were found with DR3 and DR4 [1]. Restriction fragment length polymorphism (RFLP) analyses of the HLA class II loci have suggested that DQ alleles might be even more precise markers of susceptibility to the disease than DR alleles $[2,3]$. Based on nucleotide sequence data and oligonucleotide typing it has been proposed that aspartic acid at position 57 (Asp57) on the HLA-DQ $\beta$ chain may protect against Type 1 diabetes in Caucasians [4, 5]. In Japanese, however, Asp57 seems to have no protective effect [6].

The HLA region spans over 3800 kilobases (kb) [7] and maps to chromosome 6 (band $6 \mathrm{p} 21.3$ ). It consists of several highly polymorphic loci, of which HLA-A, C and

* see Acknowledgements
B loci code for class I antigens and HLA-DR,DQ, and DP for class II antigens. Class III constitutes several genes including genes for the complement components $\mathrm{C} 2, \mathrm{C} 4$ and $\mathrm{Bf}$, which are located between class I and class II [8]. Many other loci are known and, additionally, numerous genes, which have not so far been characterized, exist in the HLA region $[9,10]$. Linkage disequilibrium between the HLA-A,C,B,DR and DQ alleles greatly complicates any attempt to pinpoint the susceptibility gene(s) to a specific HLA locus. Consequently, it may be too simplistic to explain predisposition to Type 1 diabetes by the structure of the DQ molecules alone omitting the effect of other HLA gene products.

Certain HLA haplotypes appear to be found particularly often in Type 1 diabetic subjects. In northern Europe, the haplotypes A1,Cw7,B8,DR3,DQw2 and A2,Cw3,Bw62,DR4,DQw8 are frequently found in patients with Type 1 diabetes. In Finland the haplotype A2,Cw1,Bw56,DR4 is the third most common haplotype in diabetic patients [11], and it has not so far been found in other populations. The absolute risk for Type 1 diabetes 
of this haplotype is the highest of all HLA haplotypes found in Finland [12]. Finland has the highest incidence of Type 1 diabetes in the world [13], and therefore, the conserved antigen combination of this population-specific haplotype may be highly relevant to disease susceptibility.

This study was part of a nationwide population-based prospective family study of Type 1 diabetes in Finland. Out of 757 serologically HLA genotyped families we have chosen 17 for HLA-DQ locus analysis at the molecular level. We were particularily interested in defining the DQ locus of the newly-found susceptibility haplotype A2,Cw1,Bw56,DR4. By sequencing and oligonucleotide typing of the DQB1 and DQA1 alleles, respectively, and using the RFLP technique with $D Q \alpha$ and $D Q \beta$ chain probes, we have tested whether the differences in haplotype-specific absolute risk [12] could be attributable to polymorphisms at the DQ locus.

\section{Subjects and methods}

\section{The families}

The Childhood Diabetes in Finland (DIME) study is a nationwide study into the genetic and environmental factors involved in Type 1 diabetes, which was carried out in Finland between September 1986 and April 1989. This study is the first population-based prospective family study which used HLA haplotypes as predictive markers for Type 1 diabetes. The genetic part of the study comprised 757 newlydiagnosed diabetic children aged 14 years or younger (probands). Together with their parents and siblings they were HLA-A,C,B,DR genotyped using conventional HLA serology [11].

From these genotyped families 17 were especially selected for this RFLP and sequence analysis. The families were selected for the presence of certain important HLA haplotypes such as the newlyfound susceptibility haplotype A2,Cw1,Bw56,DR4 [11]. Only families which were informative for the selected haplotypes were chosen; families where one parent was homozygous for a certain haplotype were excluded. Four of the families were multiplex families (Table 1).

The four HLA haplotypes found in each family were divided into "diabetic" and "non-diabetic" haplotypes. "diabetic" haplotypes were the two haplotypes found in the diabetic probands. "Nondiabetic" haplotypes were defined as those parental haplotypes which were not found in probands or in parents or in siblings with Type 1 diabetes.

\section{The haplotype-specific absolute risk}

The haplotype-specific absolute risk was calculated using the formula $R=\mathrm{R} 1\left(\mathrm{p}^{2}\right)+\mathrm{R} 2(2 \mathrm{pq})+\mathrm{R} 3\left(\mathrm{q}^{2}\right)$, where $R$ is the total incidence of Type 1 diabetes in the general population (age 0-14 years), which was 35/100,000 per year during 1987-1988 in Finland [13]. R1 is the incidence in homozygotes for haplotype $p, R 2$ the incidence in heterozygotes for haplotype $\mathrm{p}$ and haplotype $\mathrm{q}$, and $\mathrm{R} 3$ the incidence in homozygotes for haplotype q.

\section{The RFLP analysis}

High molecular weight DNA was extracted from peripheral blood leucocytes using a standard method [14]. Six micrograms of genomic DNA was digested with the restriction endonucleases PstI, TaqI and BamHI (New England Biolabs, Beverly, Mass., USA) according to the manufacturers instructions. After digestion DNA was electophoresed in $0.6 \%$ agarose gel for $16-20 \mathrm{~h}$ using $50 \mathrm{~V}$. Hind III digested bacteriophage lamda DNA was run as a molecular weight marker in each gel. After an alkaline denaturation step DNA fragments were capillary-blotted overnight onto a nylon filter (Hybond-N,
Amersham, Bucks.,UK). Filters were prehybridized for 6 hat $42^{\circ} \mathrm{Cin}$ $50 \%$ deionized formamide, $6 \%$ standard sodium citrate (SSC), $5 \%$ Denhardt's solution ( $2 \%$ Ficoll, $2 \%$ bovine serum albumin, $2 \%$ polyvinyl pyrrolidone), $0.5 \%$ sodium dodecyl sulphate (SDS) and herring sperm DNA $(100 \mu \mathrm{g} / \mathrm{ml})$. In the hybridization step a probe labelled with $\alpha_{-}{ }^{32} \mathrm{P}$-dCTP (Random prime, Boehringer, Mannheim, Germany) was added into the prehybridization solution and the filters were hybridized overnight at $42^{\circ} \mathrm{C}$. The probes were cDNA probes for the DQ $\alpha$ and DQ $\beta$ chains $[15,16]$. The DQ $\alpha$ probe was used in the 10 th Histocompatibility Workshop, and the DQ $\beta$ probe was kindly provided by Dr. M. Trucco (University of Pittsburgh, Pa., USA). The filters were washed in $2 \times \mathrm{SSC}$ at $25^{\circ} \mathrm{C}$ for $10 \mathrm{~min}$, and at $60^{\circ} \mathrm{C}$ for $15 \mathrm{~min}$, in $2 \times \mathrm{SSC}+0.1 \mathrm{SDS}$ at $60^{\circ} \mathrm{C}$ for $15 \mathrm{~min}$, and finally in $0.3 \mathrm{SSC}+0.1 \mathrm{SDS}$ at $60^{\circ} \mathrm{C}$ for $5-15 \mathrm{~min}$. Filters were autoradiographed for 2 and 6 days. The restriction fragment sizes were determined as the mean size obtained from different blots. There was up to $10 \%$ variation in fragment sizes between different blots.

HLA-DQ RFLP fragments for each haplotype were determined by co-segregation of the fragments with the haplotype. The assignment of an RFLP fragment to a haplotype is clear when only one parent is positive for the fragment, and both of that parent's haplotypes are inherited by the children. It is also clear when both parents are positive, and at least one child is negative for the fragment. The assignment of a fragment to a haplotype is not certain when all family members are positive for the fragment. It is also uncertain when only one haplotype of a parent is inherited by the children. In the latter case it is possible that the non-inherited haplotype is positive for the fragment as well as the inherited haplotype.

\section{The HLA-DQB1 sequence analysis}

Most of the variability of the DQB1 gene is in the second exon [8]. The HLA-DQB1 second exon was amplified twice using polymerase chain reaction (PCR) [17]. Prior to amplification genomic DNA was digested with restriction endonuclease BstEII (New England Biolabs) to avoid co-amplification of the DQB2 gene [18]. One microgram of DNA was amplified using a thermal cycler (Techne PHC1) under the following conditions: $0.2 \mathrm{mmol} / 1 \mathrm{dNTPs}, 20 \mathrm{mmol} / 1$ Tris$\mathrm{HCl}, \mathrm{pH} 8.8,15 \mathrm{mmol} / \mathrm{l}\left(\mathrm{NH}_{4}\right)_{2} \mathrm{SO}_{4}, 1.5 \mathrm{mmol} / 1 \mathrm{MgCl}_{2}, 0.1 \%$ Tween $20,0.01 \%$ gelatin, 100 pmol of primers and $2.5 \mathrm{U}$ of Taq DNA polymerase (Amplitaq, Perkin-Elmer Cetus, Emeryville, Calif., USA). Before adding the enzyme the reaction mixture was denaturated at $98^{\circ} \mathrm{C}$ for $5 \mathrm{~min}$ and then kept at $80^{\circ} \mathrm{C}$ when enzyme was added. Thereafter, the denaturation step was $1 \mathrm{~min}$ at $95^{\circ} \mathrm{C}$, annealing $1 \mathrm{~min}$ at $60^{\circ} \mathrm{C}$, and extension $2 \mathrm{~min}$ at $70^{\circ} \mathrm{C}$. After 30 cycles there was an extension step $10 \mathrm{~min}$ at $70^{\circ} \mathrm{C}$. We used the primers GLPDQ $\beta 1$ and GAMPDQX 32 [4] for the first amplification. The amplified product was run in a $3 \%$ low melting point agarose gel (NuSieve, FMC, Rockland, Me., USA) and the 240 bp fragment was excised. The excised gel slice was diluted three-fold with distilled water, and $10 \mu \mathrm{I}$ was amplified again using the same conditions as above except slightly modified primers with BamHI and HindIII sites: 5'-GATTTCGTGGATCCGTTTAAG-3' and 5'-CCACCTCGAAGCTTTGTGTGCA-3'. The amplified product was run in a $3 \%$ agarose gel (standard low- $\mathrm{m}_{\mathrm{r}}$, Bio Rad, Richmond, Calif., USA). The 240 bp product was recovered from the gel using electroelution [14]. The amplified DNA was purified with phenol and chloroform and digested with BamHI and HindIII. Nucleotide sequences were determined after subcloning fragments in the pGem7Z (Promega, Madison, Wiss., USA) by the chain-termination method [19] (Sequenase 2.0, USB, Cleveland, Ohio, USA). The amplification, cloning and sequencing was performed two-three times for each subject to rule out possible errors made by Taq-polymerase. The most recent names for DQB1 alleles recommended by the WHO Nomenclature Committee were used [20].

\section{The HLA-DQAI oligonucleotide analysis}

The amplification and the analysis of the alleles were performed using the AmpliType HLA-DQ $\alpha$ Forensic DNA Amplification and Typing Kit (Perkin-Elmer Cetus, Emeryville, Calif., USA), which 
Table 1. HLA haplotype (a, b, c, d) segregation in 17 families

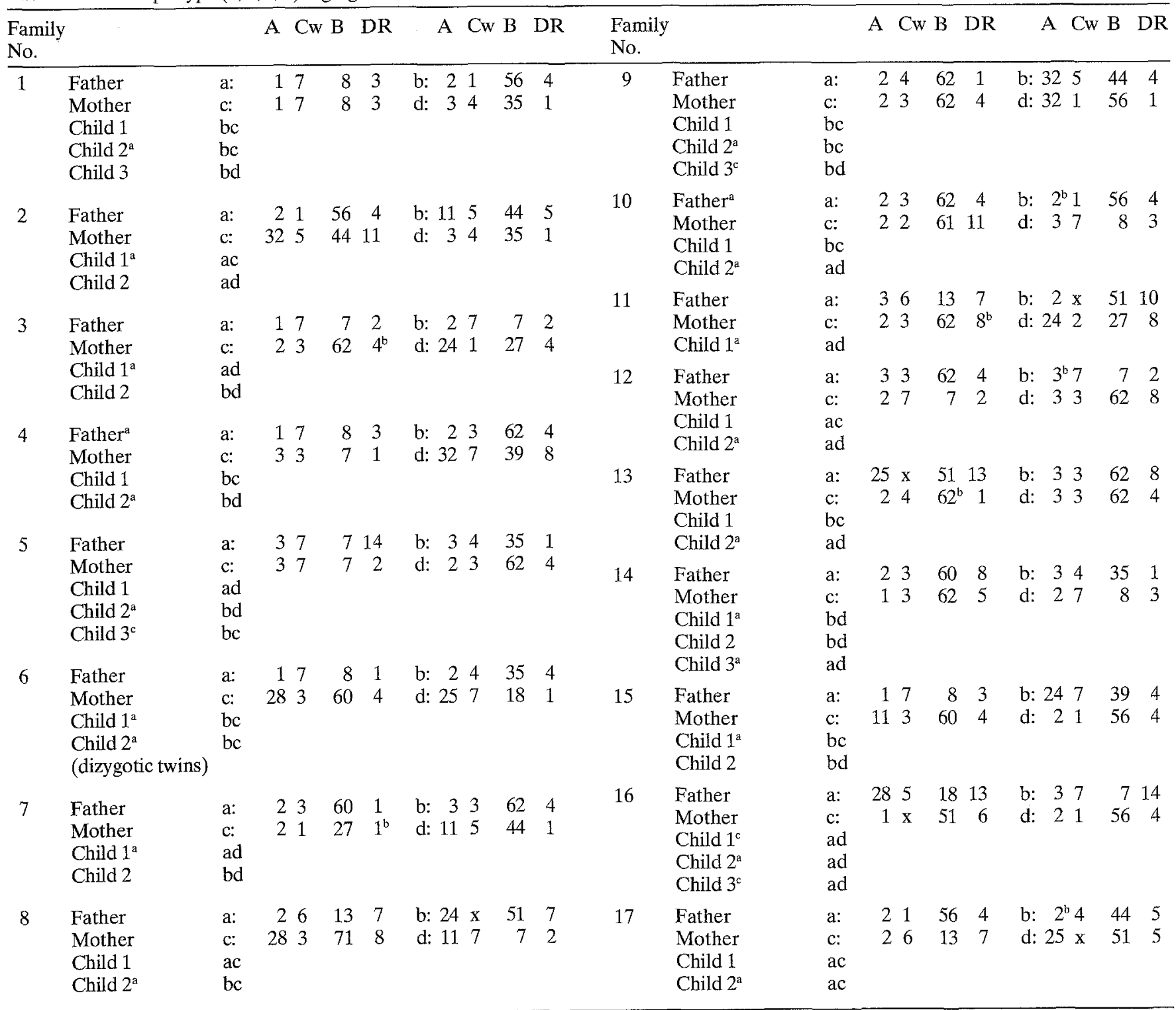

a Subject with Type 1 (insulin-dependent) diabetes, ${ }^{b}$ query homozygote, ${ }^{\circ}$ subject not RFLP typed, $x$, undefineable antigen. $\mathrm{A} 2, \mathrm{Cw} 1, \mathrm{Bw} 56, \mathrm{DR} 4$ found in six families; A3,Cw4,B35,DR1 and $\mathrm{A} 2, \mathrm{Cw} 3, \mathrm{Bw} 62, \mathrm{DR} 4$ found in four families; $\mathrm{A} 1, \mathrm{Cw} 7, \mathrm{~B} 8, \mathrm{DR} 3$ and

detects six different alleles [21]. Basically, the procedure involved amplification of the DNA segment coding for the outer domain of the HLA-DQ $\alpha$ chain by PCR using biotinylated primers. The amplified product was subsequently hybridized to a filter carrying immobilized sequence-specific oligonucleotide DNA probes. Detection of the hybridization reaction was enzymatically mediated by a streptavidine-horseradish peroxidase conjugate resulting in a visually detectable dye. The nomenclature for the DQA1 alleles has been previously published [21]. Two subjects (a parent and a child) per family were typed to confirm the co-segregation of the DQA1 alleles with the serologically defined HLA haplotype.

\section{Results}

The 68 parental HLA haplotypes found in the 17 families are presented in Table 1. Since some important haplotypes were selected to be present in several families 47 different haplotypes were found. In these families 35 of 64 (55\%) of
$\mathrm{A} 3, \mathrm{Cw} 3, \mathrm{Bw} 62, \mathrm{DR} 4$ found in three families; A2,Cw7,B7,DR2, $\mathrm{A} 3, \mathrm{Cw} 7, \mathrm{~B} 7, \mathrm{DR} 2, \mathrm{~A} 2, \mathrm{Cw} 6, \mathrm{~B} 13, \mathrm{DR} 7, \mathrm{~A} 3, \mathrm{Cw} 3, \mathrm{Bw} 62, \mathrm{DR} 8$, and A3,Cw7,B7,DR14 found in two families

the haplotypes had informative DQ $\beta$ /TaqI RFLPs, 44 of 60 (73\%) DQ D/PstI RFLPs, 18 of 48 (38\%) DQ $3 / \mathrm{BamHI}$ RFLPs, 33 of $44(75 \%)$ DQ $\alpha /$ TaqI RFLPs and 30 of 48 $(63 \%)$ DQ $\alpha /$ PstI RFLPs. Of the haplotypes, 9 of $68(13 \%)$ remained uninformative with all probe/enzyme combinations and therefore no fragments could be assigned to these haplotypes.

The RFLP results of 20 important haplotypes are summarized in Table 2. Examples of autoradiograms using each probe/enzyme combination are illustrated in Figure 1. The DR3 positive haplotypes showed no variation in DQw2 associated RFLP patterns, neither did DR7 positive haplotypes. Two families (Family 6 and 15) had non-informative RFLPs for DR4 positive haplotypes. Consequently, no fragments could be assigned to haplotypes A2,Cw4,Bw35,DR4, A28,Cw3,Bw60,DR4, A24,Cw7,Bw39,DR4, A11,Cw3,Bw60,DR4, and A2,- 
Table 2. RFLP fragments of important haplotypes increased (bold) or decreased in patients with Type 1 (insulin-dependent) diabetes mellitus. $D Q \beta$ and $D Q \alpha$ fragment sizes are in $100 \times$ base pairs

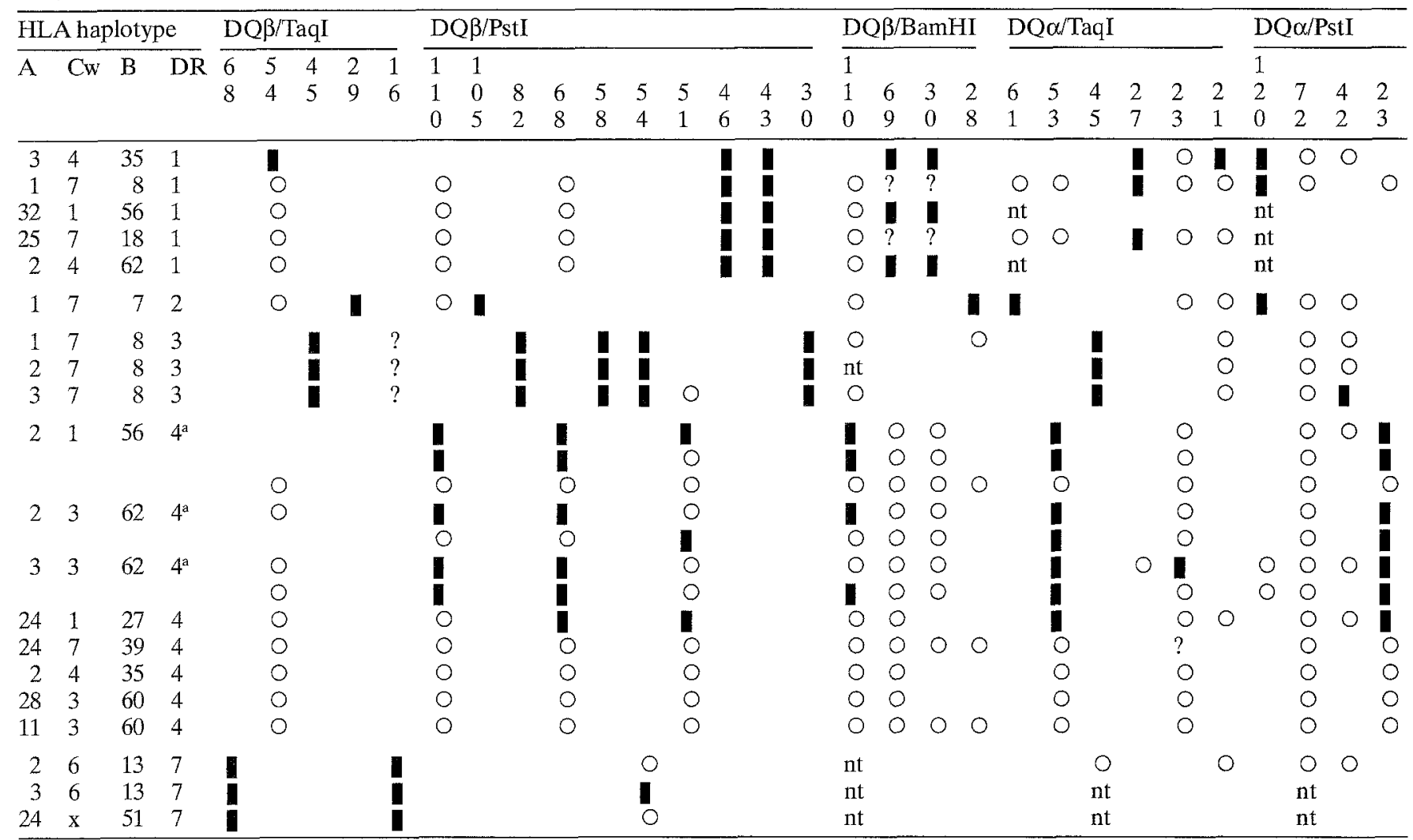

${ }^{a}$ Haplotype found in several families, some fragments not always assigned to the haplotype. I, fragment unambiguously assigned to the haplotype; ?, ambiguous fragment; $O$, fragment present but not informative in the family; $x$, undefineable antigen; nt, not tested

Cw1,Bw56,DR4 in these families. The absence of fragments associated with DQw7 (DQß/PstI 4.3 and DQß/BamHI 3.55 [22]), and the presence of fragments DQ $/$ PstI $11.0 \mathrm{~kb}, 6.8 \mathrm{~kb}, 5.1 \mathrm{~kb}$ and DQ $\beta /$ BamHI $11.0 \mathrm{~kb}$ in all members of these families suggest that these haplotypes carried the specificity DQw8. Thus, all eight DR4 positive haplotypes in Table 3 were DQw8. Three of the families (Families 7, 8, and 11) were selected for probands who where neither DR3 nor DR4 positive. Two of these probands were DR7,DQw2/DR8,DQw4, and one was DR1,DQw5/DR1,DQw5. The remaining DR1, DR2, DRw8 and DRw10 positive haplotypes in these families showed RFLP patterns corresponding to DQw5, DQw6, DQw4 and DQw5, respectively. DRw5 and DRw6 positive haplotypes showed considerable variation both in DQ $\alpha$ and DQ $\beta$ RFLPs (data not shown).

The DQA1 alleles were typed using sequence-specific oligonucleotide probes from 19 haplotypes, and the DQB1 second exon was sequenced from nine haplotypes (Table 3). These included the newly-found susceptibility haplotype $\mathrm{A} 2, \mathrm{Cw} 1, \mathrm{Bw} 56, \mathrm{DR} 4$, the two most common haplotypes in Finnish diabetic children, A1,Cw7,B8,DR3 and A2,Cw3,Bw62,DR4, and the two most frequent"non-diabetic" haplotypes in the Finnish population, $\mathrm{A} 3, \mathrm{Cw} 4, \mathrm{~B} 35, \mathrm{DR} 1$ and $\mathrm{A} 3, \mathrm{Cw} 7, \mathrm{~B} 7, \mathrm{DR} 2$. All DR1, DR2, DR3, DR4, DR7, and DR8 positive haplotypes carried DQA1 alleles DQA1.1, DQA1.2, DQA4, DQA3, DQA2, and DQA4, respectively. The DQB1 sequences correlated exactly with previously published sequences [5].
The haplotype-specific absolute risks developing Type 1 diabetes are shown in Table 4. The absolute risks have been calculated in a sample of 757 families with a newly-diagnosed diabetic child, altogether 1,424 unequivocally defined haplotypes among patients and 1,254 haplotypes among non-diabetic family members. Because the HLA haplotype data were obtained from a population-based family study, we were able to calculate the absolute risk of Type 1 diabetes associated with each haplotype found in the probands. There was a considerable variation in absolute risk among different HLA haplotypes although similar DQ $\alpha$ and DQ $\beta$ RFLPs, the same DQA1 alleles, and, in the case of the four DR4 positive haplotypes (Table 3 ) the DQB1 exon 2 sequence was shown to be identical.

\section{Discussion}

Since the families were selected for this molecular study, the HLA haplotypes of these 17 families were clearly defined by serology. The DQ $\alpha$ and DQ $\beta$ RFLPs were less informative than the serologically defined haplotypes, as would be expected when comparing polymorphicinformation content of haplotypes vs single loci. Segregation of the serologically defined HLA haplotypes in the families provided a solid basis, which greatly helped the assignment of restriction fragments to each chromosome. TaqI and PstI were the most informative restriction enzymes with DQ $\alpha$ and $D Q \beta$, respectively. Only reproducible and clearly visible fragments were included in the RFLP analysis, and, 


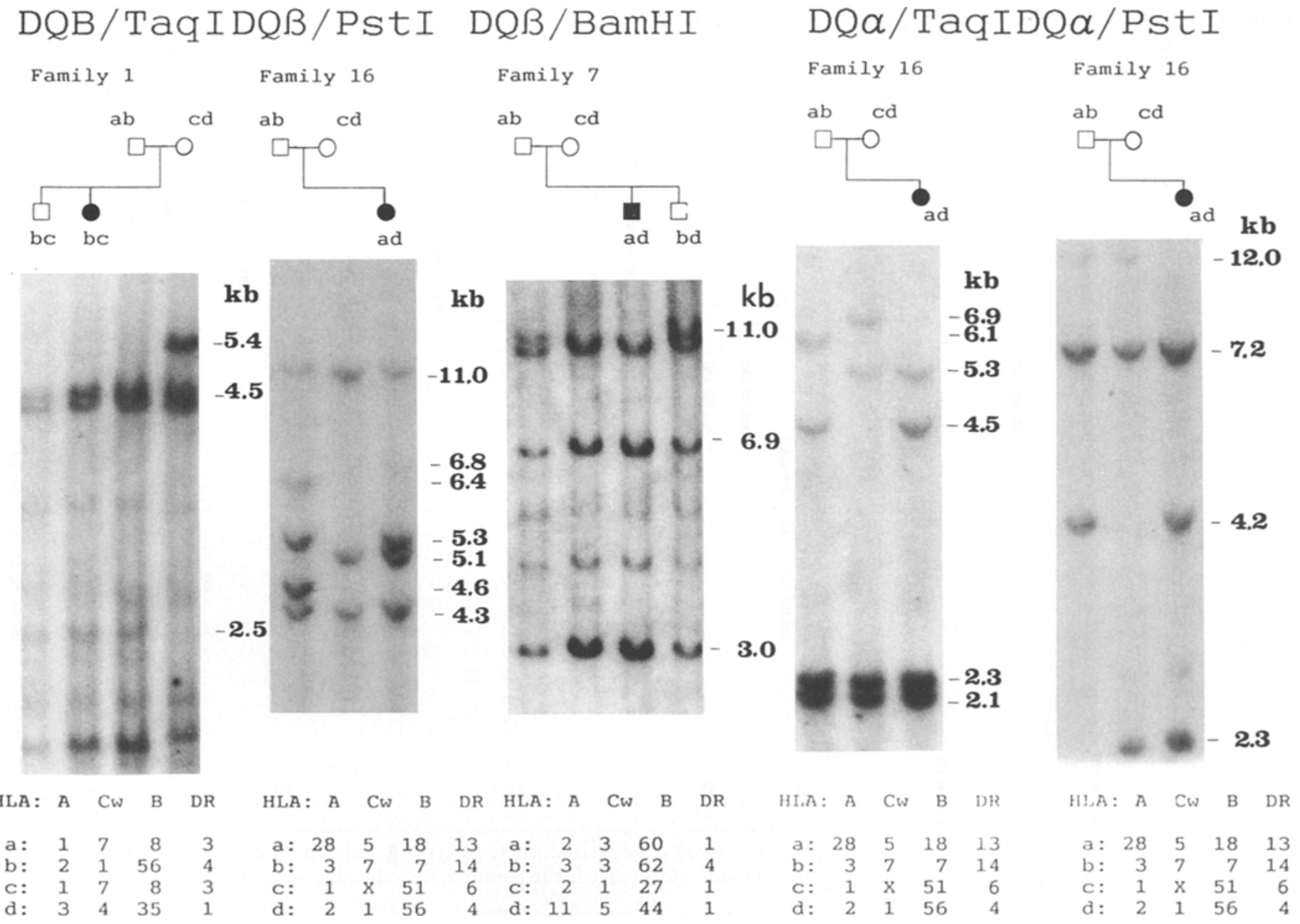

Fig.1. Examples of autoradiograms obtained with each probe and enzyme. HLA haplotype $(a, b, c, d)$ segregation is shown in the pedi- grees above. Molecular sizes of restriction fragments (in kilobases) are indicated on the right of each autoradiogram for instance, the DQw8 associated DQ $/$ TaqI $2.5 \mathrm{~kb}$ fragment was not clearly detected and was therefore excluded. DQw8 was in these families most readily defined by the presence of DQß/PstI $11.0 \mathrm{~kb}, 6.8 \mathrm{~kb}$, and $5.1 \mathrm{~kb}$ fragments, which differentiate DQw8 from DQw7 and DQw4 [23]. In DR1, DR2, DR3, DR4, DR7, DRw8, and DRw10 positive haplotypes the RFLPs were in agreement with the 10th Histocompatibility Workshop RFLP standardization reports [22-26], with the exception that certain ambiguous fragments were exluded in our analysis.

In addition to the HLA-DQ RFLPs, which are mainly based on intron polymorphism, we selected certain haplotypes to study exon polymorphism of the DQA1 and DQB1 genes. For the determination of DQB1 alleles we chose to sequence the DQB1 second exon instead of oligonucleotide typing, because sequencing allows possible new alleles to be more accurately detected. Subjects heterozygous for $\mathrm{DQ}$ were chosen for sequencing, which made it possible to assign the DQB1 sequence to one or the other haplotype.

In this study we analysed HLA-DQ $\alpha$ and DQ $\beta$ RFLPs, DQA1 oligonucleotide hybridizations, and the DQB1 exon 2 sequences of several haplotypes. We then combined these data with the haplotype-specific absolute risks estimated from previous data [12]. The large population-based sample allowed us to calculate haplotype-specific absolute risks and directly assess the true probability of the disease for subjects carrying a certain haplotype. In these families the most important DR3 and DR4 positive susceptibility haplotypes were DQw2 and DQw8, respectively. Interestingly, considerable variation could be seen in the absolute risk for developing Type 1 diabetes between haplotypes which were similar at the DQ locus. Striking differences in absolute risk were found between DR4 positive haplotypes (from 35 of 100,000 to 218 of 100,000) as well as between DR3 positive haplotypes (from 68 of 100,000 to 103 of 100,000). Unfortunately, a DR3 positive haplotype $\mathrm{A} 28, \mathrm{Cw} 7, \mathrm{~B} 8, \mathrm{BR} 3$, which proved the highest absolute risk of all DR3 positive haplotypes $(180$ of 100,000$)$ [12] was not included in the molecular analysis. The differences in haplotype-specific absolute risks suggest that there are other important genes in the HLA system, outside the DQ region, which modify the risk and make certain haplotypes more permissive to the disease.

Finland has the highest incidence of Type 1 diabetes in the world [13], and since the Finnish population is genetically homogeneous [27], it is ideally suited for the study of genetic factors in this disease. A "new" Finnish susceptibility haplotype, $\mathrm{A} 1, \mathrm{Cw} 1, \mathrm{Bw} 56, \mathrm{DR} 4$, has been described, which is the third most common haplotype in patients with Type 1 diabetes in Finland [11]. This population-specific haplotype may provide a partially genetic explanation for 
Table 3. HLA haplotypes and their DQA1 and DQB1 alleles determined by sequence-specific oligonucleotide typing and sequencing, respectively

\begin{tabular}{|c|c|c|c|c|c|c|}
\hline \multicolumn{4}{|c|}{ HLA haplotype } & \multirow[t]{2}{*}{ DQA1 } & \multirow[t]{2}{*}{ DQB1 } & \multirow{2}{*}{$\begin{array}{l}\mathrm{DQ} \beta \\
\text { codon } 5\end{array}$} \\
\hline A & $\mathrm{Cw}$ & B & DR & & & \\
\hline 3 & 4 & 35 & 1 & DQA1.1 & DQB $1 * 0501$ & Val \\
\hline 2 & 4 & 62 & 1 & DQA1.1 & DQB1*0501 & Val \\
\hline 2 & 7 & 7 & 2 & DQA1.2 & - & - \\
\hline 3 & 7 & 7 & 2 & DQA1.2 & DQB1*0602 & Asp \\
\hline 1 & 7 & 8 & 3 & DQA4 & DQB1*0201 & Ala \\
\hline 2 & 7 & 8 & 3 & DQA4 & - & - \\
\hline 3 & 7 & 8 & 3 & DQA4 & - & - \\
\hline 2 & 1 & 56 & 4 & DQA3 & DQB $1 * 0302$ & Ala \\
\hline 2 & 3 & 62 & 4 & DQA3 & $\mathrm{DQB} 1 * 0302$ & Ala \\
\hline 2 & 4 & 35 & 4 & DQA3 & DQB $1 * 0302$ & $\mathrm{Ala}$ \\
\hline 24 & 7 & 39 & 4 & DQA3 & DQB1*0302 & Ala \\
\hline 28 & 3 & 60 & 4 & DQA3 & - & - \\
\hline 11 & 3 & 60 & 4 & DQA3 & - & - \\
\hline 24 & 11 & 27 & 4 & DQA3 & - & - \\
\hline 32 & 5 & 44 & 4 & DQA3 & - & - \\
\hline 24 & $\mathrm{x}$ & 51 & 7 & DQA2 & DQB1*0201 & Ala \\
\hline 2 & 3 & 13 & 7 & DQA2 & - & - \\
\hline 28 & 3. & 71 & 8 & DQA4 & - & - \\
\hline 2 & 3 & 60 & 8 & DQA4 & - & - \\
\hline
\end{tabular}

$\mathrm{x}$, undefineable antigen

the high incidence of the disease in Finland. Other haplotypes, which are frequently found in Finnish patients are typical susceptibility haplotypes found in northern Europe such as A2,Cw3,Bw62,DR4 and A28,Cw3,Bw60,DR4.

When molecular analyses are carried out in unrelated subjects without HLA haplotype data, it is difficult to conclude whether the increased frequency of specific alleles is secondary to the increased frequency of certain haplotypes. Among patients in the United States with Type 1 diabetes a $10 \mathrm{~kb} D R \beta / T a q I$ fragment has been reportedly increased [28]. This fragment has been shown to be in linkage disequilibrium with B8,DR3, and therefore serves as an additional haplotype marker rather than as a new marker for susceptibility to Type 1 diabetes [29]. In a French series the RFLP pattern defining DR3,DQw2,Dw25 was most significantly associated with Type 1 diabetes but it was also associated with B18, and therefore primarily differentiates the southern European B18,DR3 haplotypes (not found in Finland) from B8,DR3 haplotypes [30]. Consequently, since certain HLA haplotypes occur more frequently among Type 1 diabetic patients than among control subjects, alleles detected with the more specific molecular methods provide relevant new markers for the disease only when analysed with adequate haplotype data. Whatever is detected by the molecular methods is still a part of the entire HLA haplotype due to linkage disequilibrium. Since the HLA haplotypes may cover about $3000 \mathrm{~kb}$ of DNA [7] they are excellent tools for studying genetic predisposition to Type 1 diabetes. When HLA haplotypes are used as markers for disease susceptibility it is possible to detect the effect of as yet unidentified genes of the HLA system as well as the combined effect of alleles from different loci.

Our present data indicates that in $\mathrm{Cw} 7, \mathrm{~B} 8, \mathrm{DR} 3$ and Cw3,Bw62,DR4 positive haplotypes the genes modifying the risk may be linked to the HLA-A locus since the absolute risk associated with these haplotypes varied when different A locus antigens were present. However, since the complement loci (located between class I and class II loci) were not tested variation in class III genes in these haplotypes is also possible, although it is not probable because of linkage disequilibrium between alleles at class I, class II and class III loci. Thomsen et al. [31] have proposed that in DR4 positive haplotypes the complement $\mathrm{C} 4$ locus has an effect, independent of DQw8, on susceptibility to Type 1 diabetes. Sheehy et al. [32] have found that DQw8 positive haplotypes carrying DR4 subtypes Dw4 or Dw10 conferred the highest risk for Type 1 diabetes, which may suggest that susceptibility requires specific products of both DR and DQ loci. In both above-mentioned studies the HLA-A, C and B locus antigens were not determined, which causes a dilemma: it is impossible to conclude whether the class III or the DR polymorphisms were relevant themselves, or whether they only served as additional markers for high-risk haplotypes as interpreted by Sheehy et al. [32]. This illustrates the difficulties in pinpointing the susceptibility loci in the HLA region, and stress the importance of studying whole haplotypes from $A$ to DQ locus for more definite conclusions.

Many studies indicate that the HLA-DQ polymorphism confers the major HLA linked susceptibility to Type 1 diabetes $[2-5,30]$. Our findings indicate that the most common DR3 and DR4 positive haplotypes found in Type 1 diabetic patients (typed as DQw2 and DQw8, respectively) do not show variation at the DQ locus. On the other hand, these haplotypes varied in the absolute risk they conferred, which suggests that other genes in these

Table 4. HLA haplotypes and absolute risk of developing Type 1 (insulin-dependent) diabetes mellitus associated with each haplotype

\begin{tabular}{|c|c|c|c|c|c|c|c|}
\hline \multicolumn{5}{|c|}{ HLA haplotype } & \multirow{2}{*}{$\begin{array}{l}\text { Haplotype- } \\
\text { specific } \\
\text { absolute risk }^{\mathrm{a}} \\
\text { (per } 100,000 \\
\text { per year) }\end{array}$} & \multicolumn{2}{|l|}{ Haplotypes } \\
\hline $\bar{A}$ & \multicolumn{2}{|c|}{ Cw B } & \multicolumn{2}{|c|}{$\overline{D R D Q w}$} & & $\begin{array}{l}\text { "diabetic" } \\
\text { (total 1424) } \\
n\end{array}$ & $\begin{array}{l}\text { "non-diabetic" } \\
\text { (total 1254) } \\
n\end{array}$ \\
\hline 3 & & 35 & 1 & 5 & 20 & 56 & 86 \\
\hline 1 & 7 & 8 & 1 & 5 & na & 0 & 2 \\
\hline 32 & 1 & 56 & 1 & 5 & na & 0 & 1 \\
\hline 25 & 7 & 18 & 1 & 5 & na & 2 & 2 \\
\hline 2 & 4 & 62 & 1 & 5 & na & 0 & 5 \\
\hline 1 & 7 & 7 & 2 & 6 & 8 & 1 & 4 \\
\hline 3 & 7 & 7 & 2 & 6 & 3 & 3 & 53 \\
\hline 2 & 7 & 8 & 3 & 2 & 103 & 50 & 15 \\
\hline 3 & 7 & 8 & 3 & 2 & 85 & 11 & 4 \\
\hline 1 & 7 & 8 & 3 & 2 & 68 & 134 & 59 \\
\hline 2 & & 56 & 4 & 8 & 218 & 79 & 13 \\
\hline 2 & 3 & 62 & 4 & 8 & 196 & 132 & 20 \\
\hline 24 & 7 & 39 & 4 & 8 & 166 & 45 & 8 \\
\hline 3 & 3 & 62 & 4 & 8 & 130 & 38 & 9 \\
\hline 2 & 4 & 35 & 4 & 8 & 35 & 10 & 9 \\
\hline 28 & 3 & 60 & 4 & 8 & na & 6 & 0 \\
\hline 11 & 3 & 60 & 4 & 8 & na & 2 & 3 \\
\hline 24 & 1 & 27 & 4 & 8 & na & 2 & 0 \\
\hline 2 & 6 & 13 & 7 & 2 & 54 & 30 & 17 \\
\hline 3 & 6 & 13 & 7 & 2 & na & 2 & 0 \\
\hline 24 & - & 51 & 7 & 2 & na & 1 & 1 \\
\hline
\end{tabular}

a Partly from ref. 12; na, not applicable 
haplotypes might also play an important part in modifying genetic susceptibility to Type 1 diabetes. Thus, the DQ molecules whilst important seem to account for only part of the HLA linked predisposition to the disease. More knowledge about the immunobiology of HLA is needed to understand the connection between structural polymorphisms and immunological functions in the disease process.

Acknowledgements. We thank Dr. S. Koskimies (The Finnish Red Cross, Helsinki) for donating the DQ $\alpha$ probe, Ms. A. Terola for technical assistance in DNA extraction, Mr. J. Lappivaara and Ms. A. Riikonen for serological HLA typing and technical assistance in sequencing. The DIME study group: Principal investigators: Prof. H. K. Akerblom and Prof. J. Tuomilehto. Local Investigators A. Fagerlund, M. Flittner, B. Gustafsson, A. Hakulinen, L. Herva, P. Hiltunen, T. Huhtamäki, N. P. Huttunen, T. Huupponen, M. Hyttinen, Ch. Häggqvist, T. Joki, R. Jokisalo, S. Kallio, E. A. Kaprio, U. Kaski, M. Knip, M. L. Käär, L. Laine, J. Lappalainen, J. Mäenpää, A. L. Mäkelä, K. Niemi, A. Niiranen, P. Ojajärvi, T. Otonkoski, K. Pihlajamäki, S. Pöntynen, J. Sankala, J. Schumacher, M. Sillanpää, C. H.Stråhlmann, M. R. Ståhlberg, T. Uotila, P. Varimo, M. Väre.

\section{References}

1. Svejgaard AP, Platz P, Ryder LP (1980) Insulin-dependent diabetes mellitus. In: Terasaki PC (ed) Histocompatibility 1980. University of California Press, Los Angeles, pp 638-656

2. Owerbach D, Lernmark A, Platz P et al. (1983) HLA-D region beta-chain DNA endonuclease fragments differ between HLADR identical healthy individuals and insulin-dependent diabetic individuals. Nature 303: 815-817

3. Cohen-Haguenauer O, Robbins E, Massart Cet al. (1985) A systematic study of HLA class II-beta DNA restriction fragments in insulin-dependent diabetes mellitus. Proc Natl Acad Sci USA 82: 3335-3339

4. Todd JA, Bell JI, McDevitt HO (1987) HLA-DQB gene contributes to susceptibility and resistance to insulin-dependent diabetes mellitus. Nature 329: 599-604

5. Morel PA, Dorman JS, Todd JA, McDevitt HO, Trucco M (1988) Aspartic acid at position 57 of the HLA-DQ beta-chain protects against type I diabetes: A family study. Proc Natl Acad Sci USA 85: 8111-8115

6. Yamagata K, Nakajima H, Hanafusa Tet al. (1989) Aspartic acid at position 57 of DQB chain does not protect against Type 1 (insulin-dependent) diabetes mellitus in Japanese subjects. Diabetologia 32: 762-764

7. Ziegler A, Bloemer K, Pohla H, Weiss E, Schneider P, Ragoussis J (1989) Towards a physical map of the HLA complex. In: Dupont B (ed) Immunobiology of HLA Vol II. Springer, New York, pp 75-78

8. Auffray C, Strominger JL (1986) Molecular genetics of the human major histocompatibility complex. Adv Hum Genet 15: $197-247$

9. Sargent CA, Dunham I, Campbell RD (1989) Identification of multiple HTF-island associated genes in the human major histocompatibility complex class III region. EMBO J 8: 2305-2312

10. Hanson IM, Poustka A, Trowsdale J (1991) New genes in the class II region of the human major histocompatibility complex. Genomics 10: 417-424

11. Tuomilehto-Wolf E, Tuomilehto J, Cepaitis Z, Lounamaa R and the DIME study group (1989) New susceptibility haplotype for Type 1 diabetes. Lancet II: $299-302$

12. Tuomilehto-Wolf E, Tuomilehto J, Lappivaara J, Cepaitis A and the DIME study group (1990) Estimation of haplotype specific absolute risk in Type 1 diabetes in Finland. Diabetologia 33: A44 (Abstract)

13. Diabetes Epidemiology Research International Group (1988) Geographic patterns of childhood insulin-dependent diabetes mellitus. Diabetes 37:113-119
14. Maniatis T, Fritsch EF, Sambrook J (eds) (1982) Molecular cloning. Cold Spring Harbor, New York

15. Auffray C, Lillie JW, Korman AJ et al. (1987) Structure and expression of HLA-DQ $\alpha$ and -DX $\alpha$ genes: interallelic alternate splicing of the HLA-DQ $\alpha$ gene and functional splicing of the HLA-DX $\alpha$ gene using a retroviral vector. Immunogenetics 26 : $63-73$

16. Turco E, Care A, Compagnone-Post, Robinson C, Cascino I, Trucco M (1987) Allelic forms of the alpha- and beta-chain genes encoding DQw1-positive heterodimers. Immunogenetics 26: 282-290

17. Saiki RK, Gelfand DH, Stoffel S et al. (1988) Primer-directed enzymatic amplification of DNA with a thermostable DNA polymerase. Science 239: 487-491

18. Gu XF, Elion J, Ouagued M, Clauser E, Assan R, Krishnamoorthy R (1988) A simple strategy to amplify specifically the HLA-DQ $\beta$ gene region with genomic DNA as template. Febs Lett 236: 23-26

19. Sanger F, Nicklen S, Coulson AR (1977) DNA sequencing with chain-terminating inhibitors. Proc Natl Acad Sci USA 74: 54635467

20. Bodmer JG, Marsh SGE, Albert ED et al. (1991) Nomenclature for factors of HLA system, 1990. Tissue Antigens 37: 97-104

21. Saiki R, Walsh PS, Levenson CH, Erlich HA (1989) Genetic analysis of amplified DNA with immobilized sequence-specific oligonucleotide probes. Proc Natl Acad Sci USA 86: 6230-6234

22. Hylding-Nielsen JJ, Boehm BO, Wood KJ, Bushell AR, Singal DP, Svejgaard A (1989) RFLP standardization report for DQ beta/BamHI. In: Dupont B (ed) Immunobiology of HLA Vol I. Springer, New York, pp 634-636

23. Keller E, Andreas-Zietz A, Albert ED et al. (1989) RFLP standardization report for DQ beta/PstI. In: Dupont B (ed) Immunobiology of HLA Vol I. Springer, New York, pp 613-614

24. Marcadet A, LeGall I, Cohen D et al. (1989) RFLP standardization report for DR beta/TaqI. In: Dupont B (ed) Immunobiology of HLA Vol I. Springer, New York, pp 587-589

25. Bontrop RE, Carpenter CB, Walford R, Sekiguchi S, Bignon JD, Cohen D (1989) RFLP standardization report for DQ alpha/TaqI. In: Dupont B (ed) Immunology of HLA Vol I. Springer, New York, pp 815-816

26. Hyldig-Nielsen JJ, Trucco M, Coppin H et al. (1989) RFLP standardization report for DQ alpha/PstI. In: Dupont B (ed) Immunobiology of HLA Vol I. Springer, New York, pp 809-810

27. Nevanlinna H (1972) The Finnish population structure. A genetic and genealogical study. Hereditas 71: 195-236

28. Arnheim N, Strange C, Erlich H(1985) Use of pooled samples to detect linkage disequilibrium of polymorphic restriction fragments in human disease: Studies of the HLA class II loci. Proc Natl Acad Sci USA 82: 6970-6975

29. Serjeantson SW, Kohonen-Corish MRJ, Dunckley H, Reid MA (1986) HLA class II RFLPs are haplotype-specific. Cold Spring Harbor Symposia on Quantitative Biology, Vol LI: 83-89

30. Martell M, Marcadet A, Moine A et al. (1990) Heterogeneity of HLA genetic factors in IDDM susceptibility. Immunogenetics 31: $233-240$

31. Thomsen M, Molvig J, Zerbib A et al. (1988) The susceptibility to insulin-dependent diabetes mellitus is associated with $\mathrm{C} 4$ allotypes independently of the association with HLA-DQ alleles in HLA-DR3,4 heterozygotes. Immunogenetics 28: 320-327

32. Sheehy MJ, Scharf SJ, Rowe JR et al. (1989) A diabetes-susceptible HLA haplotype is best defined by a combination of HLA DR and -DQ alleles. J Clin Invest 83: 830-835

Received: 2 September 1991

and in revised form: 4 November 1991

Dr. P.J. Tienari

National Public Health Institute

Laboratory of Molecular Genetics

Mannerheimintie 166

SF-00300 Helsinki

Finland 